\title{
IDENTIFIKASI FUNGSI DAN FASAD PECINAN PADA BANGUNAN DI RUAS JALAN SULAWESI
} MAKASSAR

\section{Marwati*1, Ikrama $^{2}$ \\ Teknik Arsitektur UIN Alauddin Makassar*1, Teknik Arsitektur UIN Alauddin Makassar ${ }^{2}$, e-mail: *1 marwati.adalle@uin-alauddin.ac.id, 2Ikrama@gmail.com}

\begin{abstract}
Abstrak_ Kawasan Pecinan dapat dilihat dari bentuk fasad bangunan sebuah kawasan. Pecinan sebagai salah satu unsur perkotaan dapat menjadi suatu pembentuk citra kota dan aset yang dapat dikembangkan menjadi komoditas melalui pengembangan kawasan wisata terutama wisata budaya dan perdagangan. Jalan Sulawesi merupakan salah satu Kawasan Pecinan di Kota Makassar. Aktivitas Perdagangan mendominasi kawasan tersebut. Adanya pergerseran bentuk fasad dari Pecinan ke modern. Penelitian ini bertujuan untuk mengidentifikasi fungsi dan fasad pecinan yang masih terlihat pada bangunan di kawasan jalan Sulawesi. Metode survey dan dokumentasi yang digunakan untuk mengidentifikasi fungsi dan fasad Pecinan. Hasil survey data kemuadian dianalisis dengan mengunakan metode deskriptif kualitatif yang disajikan dalam bentuk gambar berdasarkan zona. Hasil penelitian diketahui bahwa sebagian besar fungsi yang berada pada Jalan Sulawesi adalah toko bahan bangunan dan fasad Pecinan hanya tampak pada bagian kecil dari bangunan lama.
\end{abstract}

Kata kunci : Fungsi; Fasad Pecinan; Jalan Sulawesi.

\begin{abstract}
Chinatown area can be seen from the facade of building an area. Chinatown as one of the urban elements can be a forming of city image and assets that can be developed into commodities through the development of tourist areas, especially cultural tourism and trading. Sulawesi Street is one of Chinatown in Makassar City. Trading activities dominate in that region. The existence of Facade form friction from Chinatown to modern. This study aims to identify functions and facades of Chinatown that are still visible on the buildings in Sulawesi Street. Survey and documentation Methohs used to identify Chinatown Functions and Facades. The results of the data survey were then analyzed using qualitative descriptive methods presented in the form of images based on zones. The results of the study revealed that most of the functions located on Jalan Sulawesi were building material stores and Chinatown facades only in small sections of old buildings.
\end{abstract}

Keywords : Function; Chinatown Façade; Sulawesi Road

\footnotetext{
${ }^{1}$ Teknik Arsitektur UIN Alauddin Makassar

${ }^{2}$ Teknik Arsitektur UIN Alauddin Makassar
} 


\section{PENDAHULUAN}

Rencana pengembangan kawasan Pecinan dimasukkan ke Rencana Tata Ruang Wilayah (RTRW) Kota Makassar 2005-2015 dengan menjadikan tempat itu sebagai kawasan bisnis dan pariwisata terpadu. Namun rencana pengembangan kawasan itu belum juga terwujud. Pada umumnya bangunan di sana berfungsi sebagai toko, ("Koran Tempo," n.d.) Diakses 15 Oktober 2016. Menurut Kevin Lynch 'The Image Of The City', (1960: 46) dalam Nada (2015) bahwa "citra suatu lingkungan dapat dikenali dari beberapa elemen yaitu fasad, sirkulasi, parkir, jalur pejalan kaki, fungsi bangunan, landmark, dan pendukung aktifitas penandaan".

Menurut Prayudi (2012) bahwa "karakter visual koridor jalan Sulawesi adalah bermacammacam variasi tetapi tidak didalam suatu pola yang jelas". Hasil menunjukkan bahwa karakter dari gaya arsitektur/gaya bangunan dan pengaturan di luar gedung itu sendiri. Jalan Pecinan yang merupakan percampuran antara budaya Cina dan lokal kota Makassar. Melihat potensi yang ada, kawasan Pecinan sebagai salah satu unsur perkotaan dapat menjadi suatu pembentuk citra kota dan aset yang dapat dikembangkan menjadi komoditas melalui pengembangan kawasan wisata terutama wisata budaya dan perdagangan (Riyanto, 2004). Kosasih dalam Gobel (2009) berpendapat bahwa "kawasan Pecinan merupakan artefak kota tua yang selalu berkaitan dengan suatu tempat, peristiwa, waktu dan wujud kota. Lebih lanjut Soetomo (2009) mengemukakan bahwa "sejarah artefak kota seperti Pecinan merupakan wadah yang telah mengukir kehidupan kota dan telah membentuk nilai-nilai kekuatan dalam masyarakat yang dikenal sebagai ciri kota atau identitas yang dimiliki kota".

Pecinan diharapkan bisa menarik wisatawan baik dalam maupun luar negeri. Sehingga sebelum meresmikan kawasan Pecinan sebagai salah satu objek wisata kota, yang pelu dilakukan terlebih dahulu adalah mengaktifkan kegiatan yang berbudaya Cina, sehingga ketika orang berada di kawasan Pecinan seakan-akan mereka berada di Cina. (Darwis dalam Riyanto, 2004). Dengan melihat potensi yang ada dari nilai sejarah, arsitektural, simbolis dan estetika di kawasan tersebut, maka diperlukan suatu penataan yang dapat meningkatkan vitalitas kawasan Pecinan Makassar sebagai pusaka kota (https://id.scribd.com/document/239501855/KAWASANPECINAAN Di akses 15 Oktober 2016).

Adapun kawasan Pecinan dengan arsitektur unik merupakan pusat pertumbuhan Kota Makassar serta memiliki nilai historis yang tinggi dengan peta batas wilayah Kawasan Pecinan di Makassar. Fenomena visual kawasan Pecinan yang mulai hilang menjadi dasar untuk mengidentifikasi fasad Pecinan yang masih ada di kawasan koridor jalan Sulawesi. Tujuan pembahasan ini ialah menemukan elemen fasad yang masih kelihatan pada fasad bangunan pertokoan pada ruas jalan Sulawesi yang menjadi kawasan pertokoan kota yang perlu dipertahankan.

\section{METODE}

Metode pembahasan yang digunakan adalah survey dan dokumentasi. Data kemudian di kelompokkan berdasarkan blok yang dipisahkan antar ruas jalan yang terdapat pada Jalan Sulawesi. Kategorisasi data fasad berdasarkan fungsi bangunan yang terdapat pada ruas Jalan Sulawesi. Data dianalisis secara deskripitif kualitatif yang disajikan dalam gambar. Adapun lokasi Jalan Sulawesi dapat dilihat pada gambar berikut : 


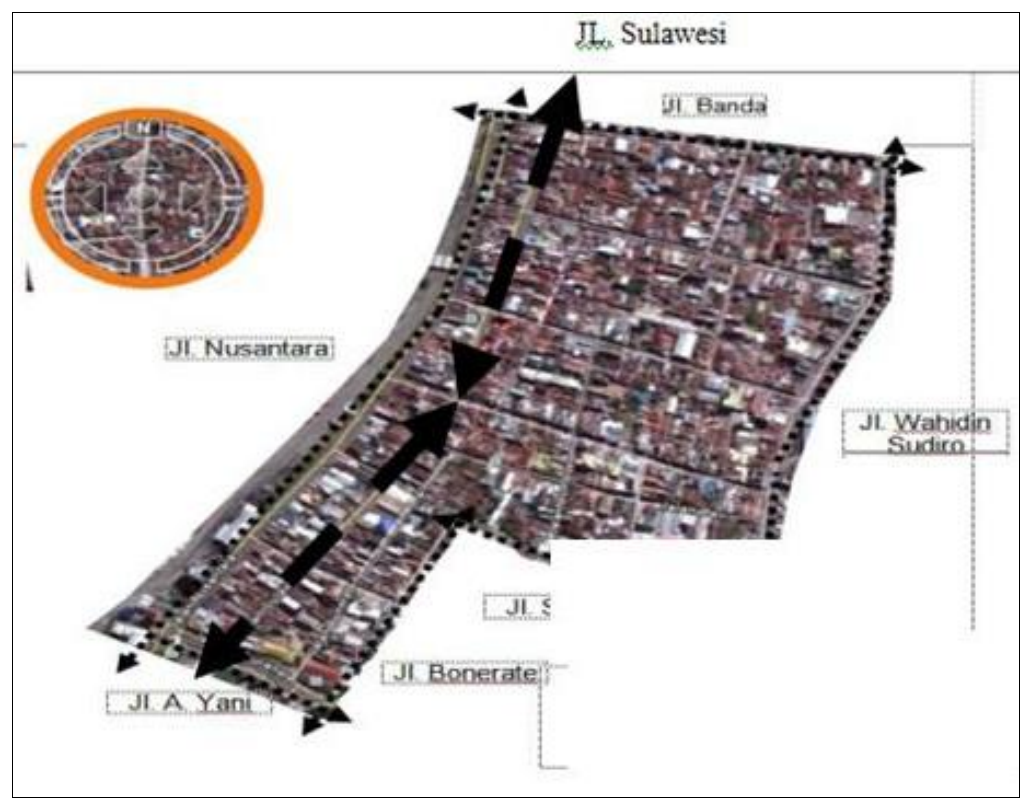

Gambar. 1: Peta Batasan wilayah kawasan Pecinan Kota Makassar

Sumber : Bappeda kota Makassar, 1991, RDTRK Makassar 2007 Akses 10 Januari 2017).

\section{HASIL DAN PEMBAHASAN}

\section{A. Fungsi Kegiatan Di Kawasan Pecinan Ruas Jalan Sulawesi}

Ruas jalan Sulawesi terdiri dari 4 kelurahan yaitu; Kelurahan Butung, Kelurahan Melayu Baru, Kelurahan Ende, dan Kelurahan Pattunuang. Identifikasi fungsi kegiatan Pecinan di ruas Jalan Sulawesi dengan panjang $1.212 \mathrm{Km}$ dan lebar $11 \mathrm{~m}$. Ruas Jalan Sulawesi merupakan salah pusat perdagangan dan perniaagaan dengan banyak toko yang menyediakaan berbagai macam jualan. Jumlah bangunan di sepanjang ruas jalan sulawesi yaitu 301 bangunan. Adapun fungsi bangunan pada ruas jalan dapat lihat pada gambar berikut ini :

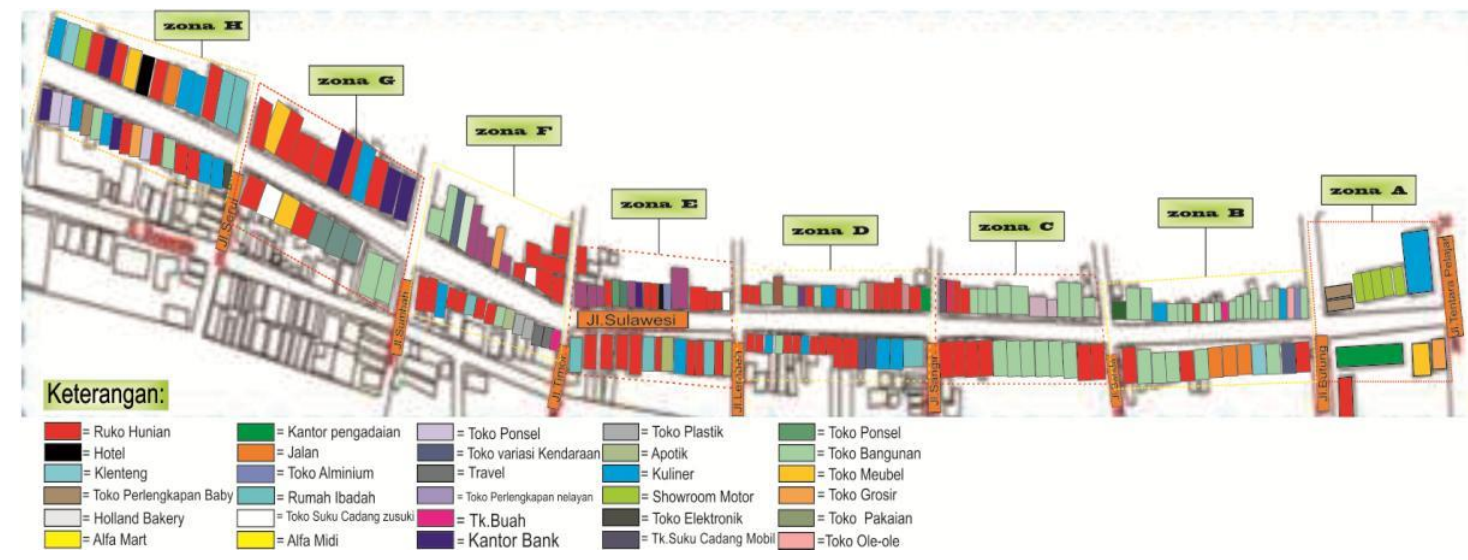

Gambar. 2 : Distribusi Fungsi Bangunan pada Ruas Jalan Sulawesi (Sumber: Hasil Olah Data Survey, 2017)

Pada (Gambar 2) terlihat perbedaan warna berdasarkan fungsi bangunan yang terdapat pada Ruas jalan Sulawesi. Fungsi toko sangat mendominasi dengan kode warna merah yang menandakan kawasan perdagangan. Adanya fungsi ibadah (Klenteng) 
memperkuat identitas Pecinan pada kawasan tersebut. Adapun jumlah dari masingmasing fungsi dapat dilihat pada tabel berikut :

Tabel. 1: Jumlah dan Fungsi Bangunan pada Ruas jalan Sulawesi Berdasarkan Zona

\begin{tabular}{|c|c|c|c|c|}
\hline NO & Zona & $\begin{array}{c}\text { Jumlah } \\
\text { Bangunan }\end{array}$ & $\begin{array}{c}\text { Jenis Kegiatan Perdagangan } \\
\text { Dan Perniagaan }\end{array}$ & $\begin{array}{c}\text { Jumlah } \\
\text { Kegiatan }\end{array}$ \\
\hline 1 & A & 11 & $\begin{array}{l}\text { Kuliner, Grosir, Bahan Bangunan,Suku Cadang } \\
\text { Kendaraan, Tekstil, Bank }\end{array}$ & $\underline{6}$ \\
\hline 2 & B & 37 & $\begin{array}{l}\text { Bahan Bangunan, Kuliner, Suku Cadang } \\
\text { Kendaraan,Pegadaian }\end{array}$ & $\underline{4}$ \\
\hline 3 & $\mathrm{C}$ & 46 & Bahan Bangunan, Travel,Tekstil,kolontong & 4 \\
\hline 4 & $\mathrm{D}$ & 48 & $\begin{array}{l}\text { Kuliner, Bahan Bangunan, Variasi } \\
\text { Kendaraan, Ponsel, Eletronik, Perlengkapan } \\
\text { baby. }\end{array}$ & 6 \\
\hline 5 & $\mathrm{E}$ & 44 & $\begin{array}{l}\text { Kuliner, Bank, Buah-buahan, } \\
\text { Apotik, Campuran, Perlengkapan fishing,'Travel }\end{array}$ & $\underline{8}$ \\
\hline 6 & $\mathrm{~F}$ & 43 & $\begin{array}{l}\text { Campuran, , Distributor Alat Kedokteran, alat } \\
\text { sport, Buah-buahan, Bank }\end{array}$ & $\underline{5}$ \\
\hline 7 & G & 42 & Kuliner, Travel,Bahan Bangunan & 3 \\
\hline 8 & $\mathrm{H}$ & 42 & $\begin{array}{l}\text { Bank, Showroom } \\
\text { motor, Kuliner, Hotel, Perlengkapan AC. Bahan } \\
\text { Bangunan. }\end{array}$ & 6 \\
\hline
\end{tabular}

Sumber : Hasil Olah Data Survey, 2017

Untuk setiap zona terrdapat bangunan yang tidak memiliki fungsi. Pada (Tabel 1), terlihat dengan jelas pada ruas Jalan Sulawesi fungsi dari tiap toko tidak tersusun dengan baik berdasarkan klaster barang dagangannya. Hal ini mengakibatkan sulitnya menemukenali fungsi bangunan tertentu berdasarkan zonanya. Pada fungsi toko dengan barang dagangan bahan bangunan mendominasi fungsi yang terdapat pada jalan tersebut. Dapat disimpulkan bahwa fungsi bangunan yang berada pada ruas jalan Sulawesi adalah multifungsi yang bergerak dalam bidang perdagangan.

\section{B. Fungsi Fasad Pecinan}

Fasad merupakan elemen Arsitektur terpenting yang mampu menyuarakan fungsi dan makna sebuah bangunan membicarakan wajah sebuah bangunan, yaitu fasad, yang kita maksudkan adalah bagian depan yang menghadap jalan. Sebagai suatu keseluruhan, fasad tersusun dari elemen tunggal, suatu kesatuan tersendiri dengan kemampuan untuk mengekspresikan diri mereka sendiri. 
Tabel. 2. Studi Preseden Bentuk Fasad Pecinan di Surabaya

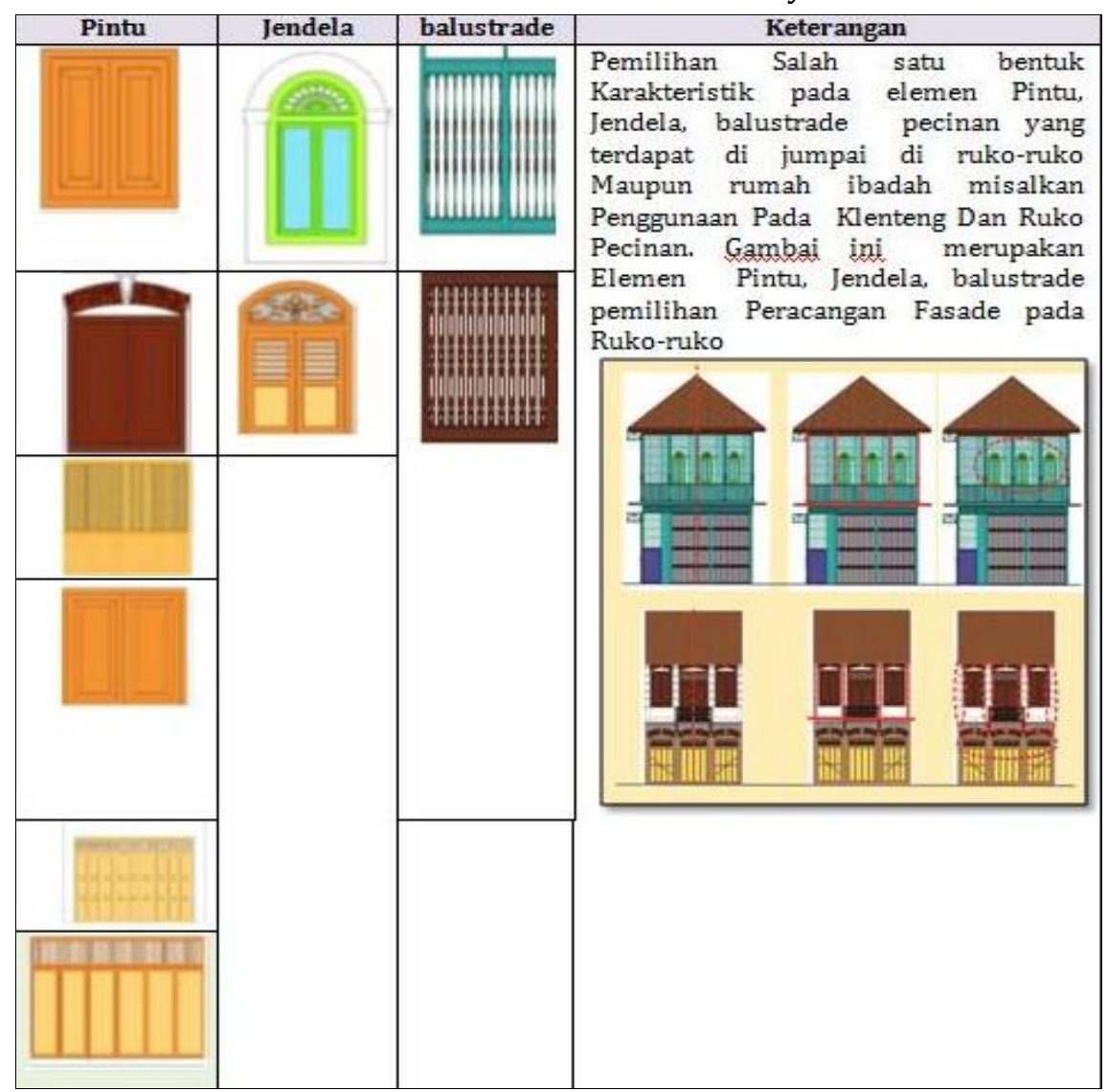

Sumber : Nada, 2015

Berdasarkan fasad Pecinan di ruas Jalan Sulawesi dikelompokkan beberapa zona sebagai berikut:
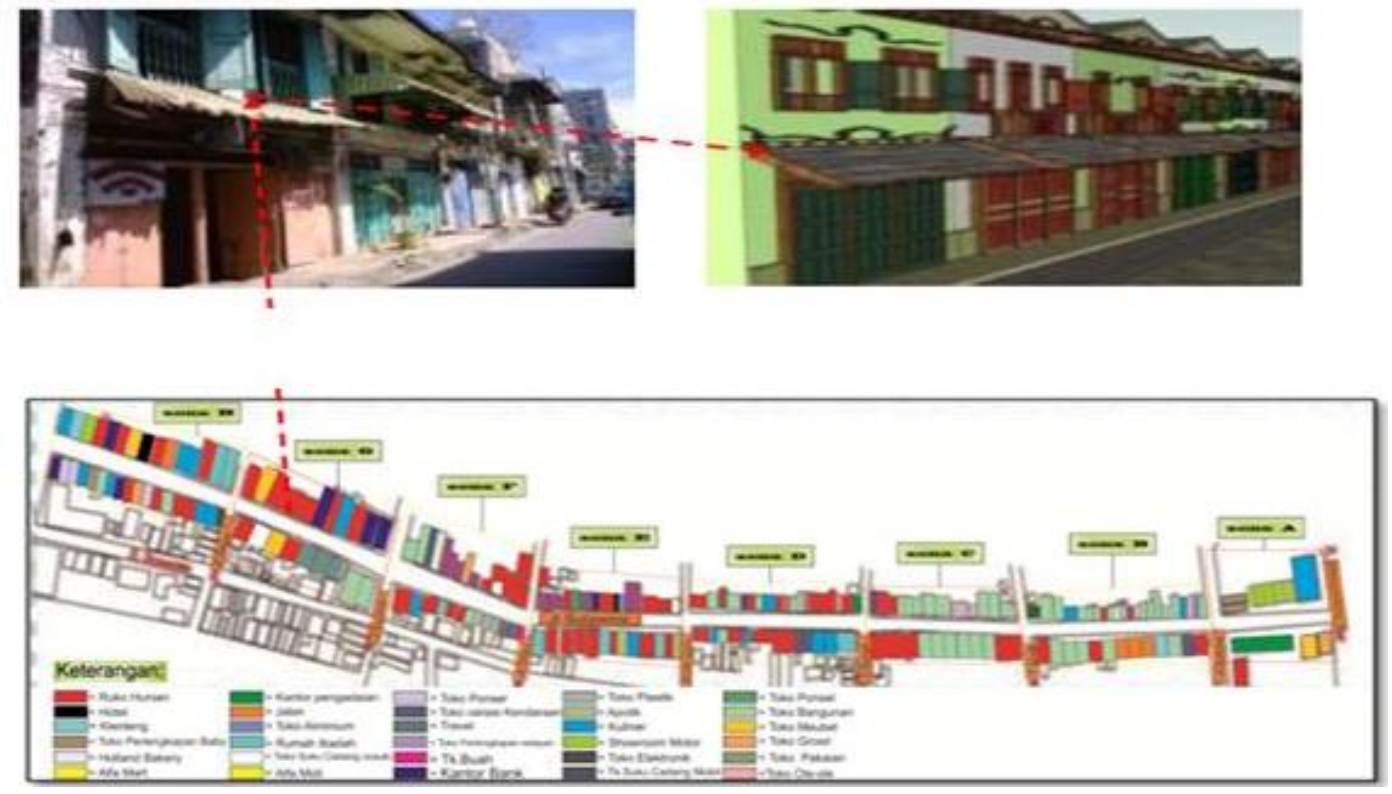

Gambar. 3: Bentuk Fasad Pecinan pada Salah Satu Sisi Jalan Sulawesi

Sumber: Hasil Olah Data Survey , 2017 
Pada (Gambar 3) masih terlihat bentuk lama bangunan toko yang masih memperlihatkan ciri fasad Pecinan. Kondisi bangunan tersebut sudah tidak terawat dan sebagian bangunan lama sudah tidak digunakan sebagai toko. Berdasarkan tabel hasil survey yang mengidentifikasi bentuk fasad Pecinan yang masih terlihat adalah sebagai berikut:

Tabel. 3: Kondisi Elemen Fasad pada Ruas Jalan Sulawesi yang Masih Dipertahankan

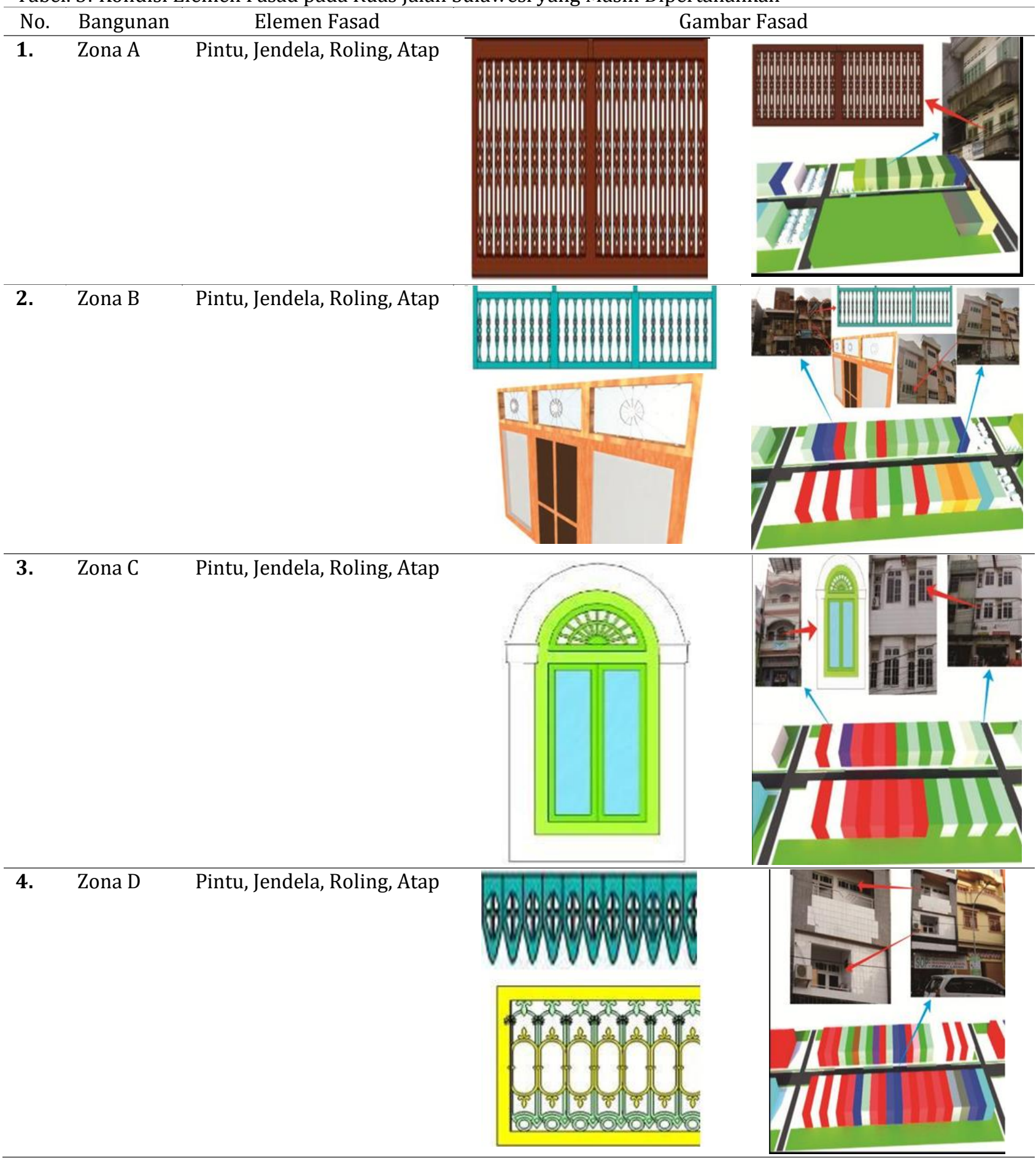


5. Zona E Pintu, Jendela, Roling, Atap

6. Zona F Pintu, Jendela, Roling, Atap
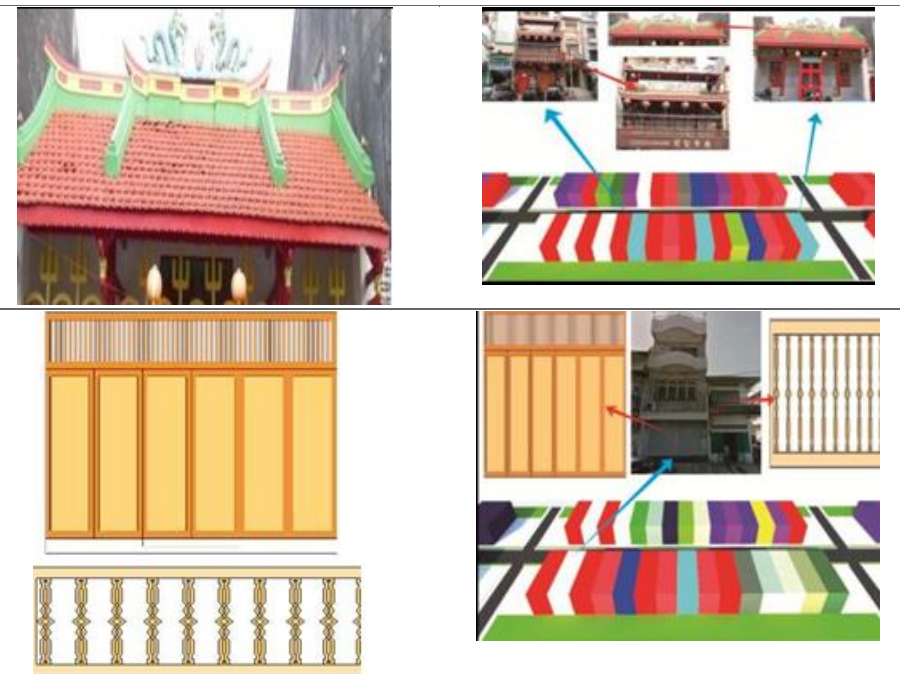

7. Zona G Pintu, Jendela, Roling, Atap
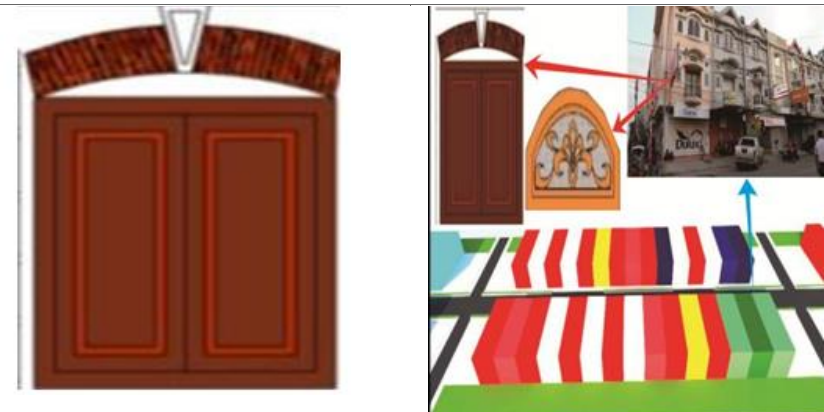

8. Zona $\mathrm{H} \quad$ Pintu, Jendela, Roling, Atap
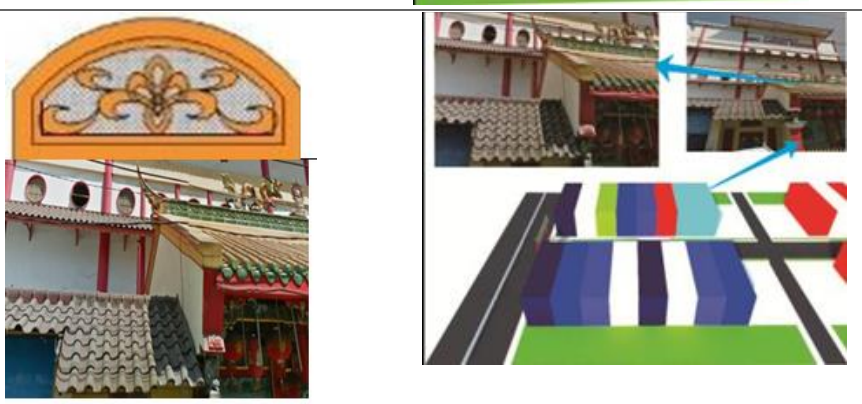

Sumber : Hasil Olah Data Survey, 2017

Berdasarkan (Tabel 3) elemen Pecinan sudah mulai tidak terlihat jelas pada bangunan toko yang ada pada ruas Jalan Sulawesi. Kesan yang timbul nuansa modern dengan penggunaan bentuik dan material modern. Hal ini jika tidak dicegah akan mengakibatkan hilangnya salah satu identitas kawasan pecinan Kota Makassar. Bentuk Melayu dengan pion-pion railing terlihat pada zona $\mathrm{F}$ dan $\mathrm{D}$. Hal ini menjelaskan $\mathrm{bahwa}$ kawasan ruas Jalan Sulawesi terdapat bentuk lain selain Pecinan

\section{KESIMPULAN}

Kondisi fungsi pada ruas Jalan Sulawesi didominasi oleh fungsi toko dalam bidang bahan bangunan. Fasad yang bernuansa Pecinan pada bangunan toko sebagian besar sudah tidak terlalu kelihatan, yang terlihat jelas elemen fasad Pecinan pada fungsi ibadah berupa ornament Pecinan. Perlunya melakukan penelitian lanjutan tentang identifikasi ornament Pecinan yang masih tersisa di kawasan Pecinan Kota Makassar agar Kota Makassar tidak kehilangan identitas Pecinannya yang bisa menjadi objek wisata heritage. 


\section{DAFTAR REFERENSI}

Bappeda kota Makassar, 1991, RDTRK Makassar 2007, Akses 10 Januari 2017 https://id.scribd.com/document/239501855/KAWASAN-PECINAAN

Zubaidi, N. C., Antariksa, A., \& Suryasari, N. (2015). Karakteristik Fasade Bangunan untuk Pelestarian Koridor Jalan Panggung Surabaya. Jurnal Mahasiswa Jurusan Arsitektur, 3(4).

Nur, K. W. (2010). Revitalisasi kawasan pecinan sebagai pusaka kota (urban heritage) Makassar (Doctoral dissertation, Tesis. Tidak Dipublikasikan. Program Pascasarjana Magister Teknik Arsitektur, ITS, Surabaya).

Nur, K. W., Darjosanjoto, E. T. S., \& Soemarno, I. (2017). Studi Perkembangan Dan Revitalisasi Pecinan Makassar. Jurnal Penataan Ruang, 7(1).

Paeni, Muchlis, dkk. 1984. Sejarah Sosial Daerah Sulawesi Selatan: Mobilitas Sosial kota Makassar 1900-1950. Jakarta: Departemen Pendidikan dan Kebudayaan.

Pelras, Christian. 2005. Manusia Bugis. Jakarta: Penerbit Nalar.

Pakilaran, A. U. (2006). Transformasi Bentuk dan Ruang pada Rumah Toko di Kawasan Pecinan, Makassar (1970-2005). Doctoral dissertation, Tesis Program Magister. Tidak Dipublikasikan. Bandung: Institut Teknologi Bandung.

Pratiwo (2010:2018) Arsitekur Tradisional Thionghoa dan Perkembangan Kota 2010. Yogyakarta, Perpustakaan Nasional : Katalog Dalam Terbitan, Penerbit Ombak, 2010.

Prayudi Kresna Batara Tandipanga and, Slamet Sudibyo (2012) Karakter Visual Kawasan Pecinan Makassar (Studi Kasus: Jalan Sulawesi). UNSPECIFIED thesis,

UNSPECIFIED. Republika, Rabu,19 Maret 2003 hlm.12.

Tandipanga, P. K. B. (2012). Karakter Visual Kawasan Pecinan Makassar (Studi Kasus: Jalan Sulawesi) (Doctoral dissertation, [Yogyakarta]: Universitas Gadjah Mada). 